\title{
Chronic Right Ventricular Pacing in the Heart Failure Population
}

\author{
Justin Gould ${ }^{1,2} \cdot$ Benjamin Sieniewicz ${ }^{1,2} \cdot$ Bradley Porter ${ }^{1,2} \cdot$ Baldeep Sidhu ${ }^{1,2} \cdot$ Christopher A. Rinaldi $^{1,2}$
}

Published online: 12 February 2018

(C) The Author(s) 2018. This article is an open access publication

\begin{abstract}
Purpose of Review We review the trials that have demonstrated potentially harmful effects from right ventricular (RV) apical pacing as well as reviewing the evidence of alternative RV pacing sites and cardiac resynchronization therapy (CRT) for patients who have heart failure and atrioventricular (AV) block.

Recent Findings The role of CRT in patients with AV block and impaired left ventricular function remains an important consideration. The BLOCK HF trial demonstrated better outcomes with CRT pacing over RV pacing in patients with left ventricular systolic dysfunction (LVSD) and AV block who were expected to have a high RV pacing burden, but failed to demonstrate a mortality benefit.

Summary CRT seems to have a beneficial effect on left ventricular reverse remodeling, systolic function, and clinical outcomes in patients with New York Heart Association (NYHA) functional class I-III heart failure, moderate to severe LVSD, and AV block compared to RV pacing. However, it is less clear whether there is a similar benefit from CRT in patients with a high percentage of $\mathrm{RV}$ pacing who have normal or mild LVSD in the treatment of AV block.
\end{abstract}

Keywords Chronic right ventricular pacing $\cdot$ Cardiac resynchronization therapy $\cdot$ CRT $\cdot$ Biventricular $\cdot$ Heart failure

$\begin{array}{ll}\text { Abbreviations } \\ \text { 2D } & \text { 2-dimensional } \\ \text { 3D } & \text { 3-dimensional } \\ \text { 6MWT } & \text { 6-min walk test } \\ \text { AV } & \text { Atrioventricular } \\ \text { CRT } & \text { Cardiac resynchronization therapy } \\ \text { CRT-D } & \text { Cardiac resynchronization therapy defibrillator } \\ \text { CRT-P } & \text { Cardiac resynchronization therapy pacemaker } \\ \text { ESC } & \text { European Society of Cardiology } \\ \text { HBP } & \text { His bundle pacing } \\ \text { HF } & \text { Heart failure } \\ \text { ICD } & \text { Implantable cardioverter-defibrillator } \\ \text { LBBB } & \text { Left bundle branch block } \\ \text { LV } & \text { Left ventricular } \\ \text { LVEDD } & \text { Left ventricular end-diastolic dimension }\end{array}$

This article is part of the Topical Collection on Nonpharmacologic Therapy: Surgery, Ventricular Assist Devices, Biventricular Pacing, and Exercise

Justin Gould

justin.s.gould@kcl.ac.uk

1 King's College London, London, UK

2 Guy's and St Thomas' NHS Foundation Trust, London, UK
LVEF Left ventricular ejection fraction

LVESV Left ventricular end-systolic volume

LVSD Left ventricular systolic dysfunction

ms Milliseconds

NYHA New York Heart Association

RV Right ventricular

RVHS Right ventricular high septum

TTE Transthoracic echocardiogram

vs. Versus

\section{Introduction}

Right ventricular (RV) pacing is an important and effective treatment in patients with atrioventricular (AV) block. RV pacing restores the heart rate to a pre-determined rate; however, a high RV apical pacing percentage/burden may promote left ventricular systolic dysfunction (LVSD) [1-9]. Alternative $\mathrm{RV}$ pacing sites have been explored to combat this problem as well as investigating cardiac resynchronization therapy (CRT) in patients with AV block with mild to severe heart failure. CRT is an effective therapy to improve symptoms and reduce mortality in patients with dyssynchronous heart failure [10]. CRT has consistently demonstrated benefit in treating patients with systolic heart failure and interventricular conduction 
delay, typically with left bundle branch block (LBBB) [11-13]. However, numerous trials have used moderate and high-degree AV block in their exclusion criteria to independently evaluate the effects of CRT without the potential cofounding detrimental effects of RV pacing [14••]. Notwithstanding, several studies have demonstrated the deleterious effects of RV apical pacing, and therefore alternative RV pacing sites have been explored as well as using CRT for patients with narrow QRS and/or mild to moderate heart failure in patients who are predicted to require a significant amount of RV pacing [15]. In the present review, we review the trials that have demonstrated potentially harmful effects from RV apical pacing as well as reviewing the evidence of alternative RV pacing sites and CRT for patients who have heart failure and AV bock (Block HF and BioPace trials).

\section{Chronic Right Ventricular Pacing and Its Deleterious Effects}

Single- or dual-chamber RV pacing is the mainstay of treatment for symptomatic AV block. However, there is increasing evidence of potential adverse effects with chronic RV apical pacing secondary to mechanical and electrical dyssynchrony $[16,17]$. The detrimental effects from chronic RV pacing including the manifestation of heart failure, adverse left ventricular (LV) remodeling, and LVSD have repeatedly been reported [1-9]. These include a wide array of structural changes incorporating left atrial and LV remodeling, LV wall thickness, and functional mitral regurgitation [18-21]. In patients with complete AV block, both cellular and intracellular changes have been described including degenerative fibrosis [22]. The Dual Chamber and Implantable Defibrillator (DAVID) trial enrolled patients undergoing implantable cardioverterdefibrillator (ICD) implantation without bradycardia or AV block and randomized them to either DDD pacing at 70 beats/min or VVI backup pacing at 40 beats $/ \mathrm{min}$. The DAVID trial identified significantly more heart failure and cardiovascular events in the DDD group with a higher percentage of RV apical pacing [5]. Similarly, the Mode Selection Trial (MOST) demonstrated that RV apical pacing may lead to heart failure; however, the loss of AV synchrony itself was shown to probably be less important. The MOST investigators found a significantly increased risk of heart failure events in both single- and dual-chamber pacing modes, with a threshold for adverse outcomes with an RV pacing percentage greater than $40 \%$ [15, 23]. The Multicenter Automated Defibrillator Implantation Trial (MADIT II) randomized patients with ischemic cardiomyopathy and left ventricular ejection fraction (LVEF) $\leq 30 \%$ to ICD therapy versus (vs.) conventional medical therapy. MADIT II showed that ICD therapy reduced total mortality [24]. A subsequent subanalysis showed that patients with a high RV pacing percentage had a significantly increased risk of new or worsening heart failure [24, 25•]. The potentially harmful effects of long-term RV pacing may occur in patients with both preserved and reduced LV systolic function; however, they are more prominent in patients with a reduced LVEF at baseline. The true incidence of LV remodeling secondary to RV apical pacing is not known; however, it is widely recognized to occur where RV pacing is $>40 \%$ of the time [23]. However, there are some pacing-dependent patients who have $100 \%$ RV pacing who do not develop LV dysfunction for reasons that are unknown [26].

\section{Pathophysiology of the Detrimental Effects of Right Ventricular Pacing}

Several clinical studies have established the potential adverse effects of chronic RV pacing on LV function. The exact pathophysiological process underpinning the deleterious effects from chronic RV pacing is not clear. RV apical pacing may have adverse effects on hemodynamics, remodeling, mechanical function, myocardial metabolism, and perfusion due to mechanical and electrical dyssynchrony [15, 27, 28]. An LBBB-type pattern is widely recognized to develop immediately following RV apical pacing. Early activation of the RV apex subsequently causes mechanical dyssynchrony as well as increasing early systolic shortening which results in prestretch of the late-activated regions and subsequent premature relaxation $[15,29,30]$. As a result, changes in LV mechanical and electrical activation due to RV apical pacing may lead to a decrease in cardiac output as well as intraventricular and interventricular dyssynchrony resulting in LVSD. This has been demonstrated in a number of studies using Doppler and strain analysis on 2-dimensional (2D) and 3-dimensional (3D) transthoracic echocardiogram (TTE) [8, 15, 27, 28, 30-34]. In addition, reduced ventricular diastole and increased ventricular systole may lead to reduced coronary perfusion [15]. Interestingly, with chronic RV apical pacing, up to $65 \%$ of patients have been found to have myocardial perfusion defects in the pacing region in the absence of flow-limiting coronary artery disease [35-37].

\section{Alternate Right Ventricular Pacing Sites}

The advent and safety of active fixation leads has facilitated the exploration of alternatives to the traditional apical RV pacing site. However, using other RV pacing sites such as RV outflow tract and septal pacing on their own may not be sufficient to circumvent the detrimental effects of chronic RV pacing. This might be explained by technical difficulties with lead placement as well as no clear evidence of superiority of RV high septal pacing, not to mention evidence of worsening LVEF with any RV pacing site [15]. The PROTECT-PACE 
study randomized 240 patients with high-grade AV block requiring $>90 \%$ ventricular pacing and preserved baseline $\mathrm{LVEF}>50 \%$, to receive pacing at the RV apex $(n=120)$ or right ventricular high septum (RVHS) $(n=120)$. At 2 years, LVEF decreased in both the RV apex ( $57 \pm 9$ to $55 \pm 9 \%, P=$ $0.047)$ and the RVHS groups $(56 \pm 10$ to $54 \pm 10 \%, P=$ $0.0003)[38 \bullet$. However, there was no significant difference in intra-patient change in LVEF between confirmed RVA and RVHS lead position $(P=0.43)$ [38•]. Similarly, there were no significant differences in heart failure hospitalization, mortality, burden of atrial fibrillation, or plasma brain natriuretic peptide levels between the two groups [38•]. A significantly greater time was required to place the lead in the RVHS position (70 \pm 25 vs. $56 \pm 24 \mathrm{~min}, P<0.0001)$ with longer fluoroscopy times ( $11 \pm 7$ vs. $5 \pm 4 \mathrm{~min}, P<0.0001)$. The authors concluded that in patients with high-grade AV block and preserved LV function requiring a high percentage of ventricular pacing, RVHS pacing does not provide a protective effect on LV function over RVA pacing in the first 2 years [38•].

His bundle pacing (HBP) is an alternative way to perform bradycardia pacing. The His-Purkinje conduction system allows the impulse generated by the sinoatrial node to rapidly propagate into both right and left ventricles which facilitates synchronized ventricular contraction. Early studies demonstrated distal HBP was able to normalize bundle branch block and QRS morphology [39]. The first successful series of permanent direct HBP was performed in 18 patients with atrial fibrillation (AF) and dilated cardiomyopathy in 2000 where the investigators found improvements in LV dimensions and cardiac function [40]. HBP may provide physiological activation thereby avoiding ventricular dyssynchrony and preserving LV systolic function in patients with a narrow QRS duration, and several studies have suggested a potential beneficial effect over RV pacing [41-45]. HBP may therefore be a way to avoid the potential deleterious effects of RV pacing; however, further randomized studies including The His Optimised Pacing Evaluated for Heart Failure (HOPE-HF) trial will be important in determining this.

There have been several studies examining CRT-based approaches to avoid the detrimental effects of apical RV pacing in patients with AV block and normal, mild, or moderate LVEF. PACE, PREVENT HF, and BLOCK HF have all directly compared CRT with RV pacing in patients with an indication for bradycardia pacing who were likely to require a high percentage of RV pacing (Table 1). These studies recruited patients in both sinus rhythm and AF. CRT has been shown to have advantages over RV pacing in four randomized clinical trials [14••, 46, 47, 53, 54]. There have also been smaller trials that have demonstrated an advantage of CRT pacing over RV pacing [33, 50, 51]. However, both BioPace and PREVENT HF have not been able to demonstrate a statistically significant benefit of CRT pacing over RV pacing in similar cohorts $[48,52 \bullet \bullet, 55]$. All other trials included in
Table 1 have shown CRT pacing to favor over RV pacing, irrespective of New York Heart Association (NYHA) class, baseline LV systolic function, degree of reverse remodeling, or QRS duration [26].

The Pacing to Avoid Cardiac Enlargement (PACE) trial was a prospective, double-blinded, randomized, multicenter study where patients with bradycardia and preserved LVEF were randomized to receive CRT $(n=89)$ or RV apical pacing $(n=88)$ [49]. Co-primary endpoints were LVEF and left ventricular end-systolic volume (LVESV) measured by 2D TTE. Patients were followed-up with a mean duration of $4.8 \pm$ 1.5 years (2.5-7.8 years), and analyses of the primary endpoint were performed in 146 patients (CRT group $n=72$, RV apical pacing group $n=74$ ). The LVESV and LVEF remained unchanged in the CRT group whereas in the RV apical pacing group, not only did the LVEF decrease, the LVESV also increased progressively at follow-up [49]. The differences in LVEF between the RV apical pacing and CRT pacing groups were $-6.3 \%$ at 1 year, $-9.2 \%$ at 2 years, and $-10.7 \%$ at longterm follow-up (all $P<0.001$ ). The corresponding differences in LVESV were +7.4 milliliters $(\mathrm{mL})$ at 1 year, $+9.9 \mathrm{~mL}$ at 2 years, and $+13.1 \mathrm{~mL}$ at long-term follow-up (all $P<0.001$ ) [49]. In addition, the detrimental effects of RV apical pacing consistently occurred in all pre-defined subgroups (age groups, gender, QRS duration, pre-existing LV diastolic dysfunction, as well as pre-existing diabetes, hypertension, and coronary artery disease). Patients in the PACE trial with RV apical pacing had a significantly higher prevalence of heart failure hospitalization than the CRT group (23.9 vs. $14.6 \%$, log-rank $\chi^{2}=7.55, P=0.006$ ) [49]. The authors concluded that CRT was superior to RV apical pacing in the prevention of LV adverse remodeling and reduction of LVEF at 1 and 2 years follow-up. The Homburg Biventricular Pacing Evaluation (HOBIPACE) and the Conventional Versus CRT Pacing in Heart Failure and Bradyarrhythmia Therapy (COMBAT) studies were both small randomized studies that found CRT pacing superior to conventional RV apical pacing in terms of improvement in quality of life, exercise capacity, and LVEF as well as reduction in LV volumes [9, 50, 51]. HOBIPACE was a prospective, randomized crossover study where 30 patients, who had AV block, LVSD defined by a left ventricular end-diastolic diameter (LVEDD) $\geq 60 \mathrm{~mm}$, and an LVEF $\leq 40 \%$ with NYHA II-IV, were randomized to 3 months of RV pacing then 3 months of CRT pacing or vice versa.

The COMBAT trial was a prospective, multicenter, randomized, double-blind crossover study that enrolled 60 patients with pacing indications for AV block with an LVEF < $40 \%$ and NYHA class II-IV for a mean follow-up period of $17.5 \pm 10.7$ months. All patients underwent CRT device implantation and were randomized to two groups and received the following for 3 months: Group A received RV pacingCRT pacing-RV pacing and group B received CRT pacingRV pacing-CRT pacing. There were significant improvements 


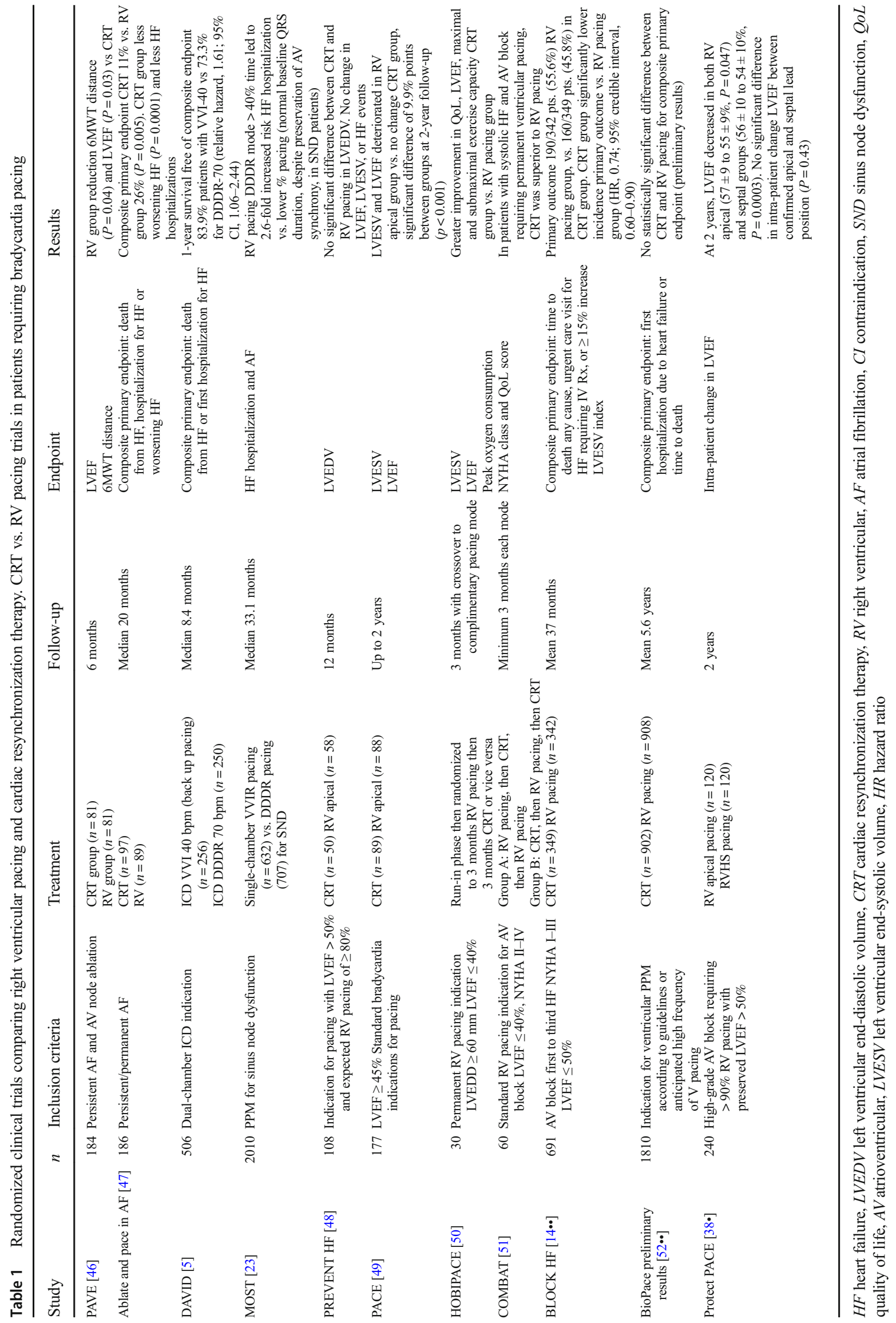


in LVEF, LVESV, NYHA class, and quality of life questionnaire scores in the CRT group compared to the RV pacing group. Death was more frequent with RV pacing; however, 6-min walk test (6MWT) distance and $\mathrm{VO}_{2 \max }$ were not significantly different between the two groups [51].

\section{BLOCK-HF and BioPace Studies}

To date, the most significant study to assess the benefits of CRT over RV pacing is the Biventricular versus Right Ventricular Pacing in Heart Failure Patients with Atrioventricular Block (BLOCK HF) trial. This was a large, multicenter, double-blind randomized study that assessed whether CRT reduced adverse LV remodeling, morbidity, and mortality in patients with AV block with a standard class I or IIa indication for ventricular pacing, NYHA class I-III heart failure, and $\mathrm{LVEF} \leq 50 \%$ [14••]. Patients received a CRT pacemaker (CRT-P) unless they had an indication for defibrillation therapy in which case they received a CRT implantable cardioverter-defibrillator (CRT-D) and were randomized to receive either CRT pacing or standard RV pacing. Patients with standard indications for CRT, based on the guidelines during the recruitment phase, were excluded from recruitment as were patients with recent or acute myocardial infarction, unstable angina, percutaneous or surgical coronary revascularization within 30 days, or severe valvular heart disease with an indication for repair or replacement $[14 \bullet \bullet, 15]$. The primary outcome was time to death from any cause, $\geq 15 \%$ increase in LVESV index, or an urgent care visit for heart failure that required intravenous therapy. Nine hundred eighteen patients were enrolled, but only 691 patients underwent randomization in a 1:1 ratio. Patients were followed-up every 3 months with a mean follow-up duration of 37 months. The primary outcome occurred in 190 of 342 patients (55.6\%) in the RV pacing group and 160 of 349 (45.8\%) in the CRT group (hazard ratio, $0.74 ; 95 \%$ credible interval, 0.60 to 0.90 ). with a posterior probability of a hazard ratio $<1$ was 0.9978 , exceeding the threshold of 0.9775 for a significant different between the two groups (Fig. 1) [14••]. Similar findings were noted in patients receiving a CRT-P or CRT-D. Removing the echocardiographic volumetric indices from the analysis, death from any cause or an urgent care visit for heart failure still showed a significant difference in favor of CRT pacing compared to RV pacing with a hazard ratio of 0.73 (95\% credible interval, 0.57 to $0.92)[14 \cdot \bullet, 15]$. Of note, $6.4 \%$ of patients had a complication documented secondary to LV lead implantation. A subsequent substudy of BLOCK HF demonstrated reverse remodeling within the CRT group using 2D TTE, where CRT pacing significantly reduced intraventricular mechanical delay and LV volume indices along with improvement in LVEF compared to RV pacing, all indicating $\mathrm{LV}$ reverse remodeling. The risk of morbidity and mortality was estimated to increase by

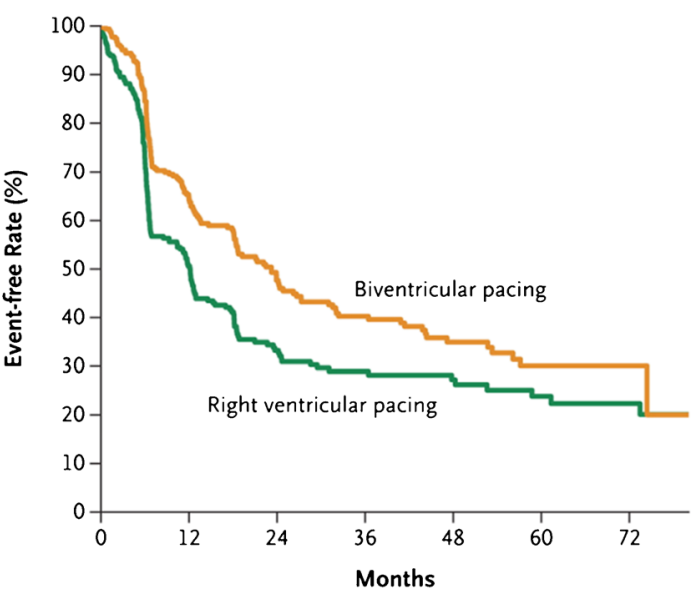

No. at Risk

$\begin{array}{lllllllr}\text { Biventricular pacing } & 349 & 161 & 87 & 62 & 38 & 17 & 3\end{array}$ $\begin{array}{llllllll}\text { Right ventricular } & 342 & 126 & 59 & 39 & 28 & 18 & 10\end{array}$ pacing

Fig. 1 Freedom from composite primary endpoint (time to death from any cause, $\geq 15 \%$ increase in LVESV index, or an urgent care visit for heart failure that required intravenous therapy) in the BLOCK HF trial, copyright ${ }^{\circledR} 2013$ Massachusetts Medical Society, reprinted with permission

up to $1 \%$ for every $1 \mathrm{~mL} / \mathrm{m}^{2}$ increase in LVESV index, suggesting LVESV index may be predictive of morbidity and mortality [56]. The main limitation of BLOCK HF was a high crossover rate from the RV pacing group to CRT group as well a reasonably large amount of missing 2D TTE data.

The preliminary results of the Biventricular Pacing for Atrioventricular Block to Prevent Cardiac Desynchronisation (BioPace) trial were announced in 2014 [52••, 55]. BioPace was a multicenter, randomized, single-blind study conducted in Europe and aimed to investigate the hypothesis that CRT pacing is superior to RV pacing in patients with AV block requiring permanent ventricular pacing. The combined primary endpoint was first hospitalization secondary to heart failure or time to death. Main inclusion criteria were patients with an indication for implantation of a ventricular pacemaker according to European Society of Cardiology (ESC) guidelines and an anticipated need for frequent ventricular pacing with any LVEF as measured by TTE. Patients with first, second, and third AV block were enrolled. For first-degree AV block, the defining PR interval was $\geq 220$ milliseconds (ms) with an indication for pacing. Patients with permanent AF were also included providing their spontaneous ventricular rate was $\leq 60$ beats/min at rest. One thousand eight hundred ten patients were recruited, and 902 patients were assigned to the CRT group and 908 to the RV pacing group. The patient demographics were largely similar to BLOCK HF except the average LVEF in BioPace was 55\% compared to approximately $40 \%$ in Block HF. The preliminary results from BioPace showed no statistically significant difference between CRT pacing and RV pacing for first hospitalization secondary to heart failure or time to death. However, there was a non- 
Table 2 Summary of 2016 ESC Guidelines for the diagnosis and treatment of acute and chronic heart failure relating to CRT and $\mathrm{RV}$ pacing in patients with highdegree AV Block. Adapted from 2016 ESC Guidelines for the Diagnosis and Treatment of Acute and Chronic Heart Failure [61••]

\begin{tabular}{llc}
\hline ESC recommendation & Class & Level \\
\hline $\begin{array}{l}\text { CRT is recommended over RV pacing for patients in sinus rhythm or AF, with HFrEF } \\
\text { of any NYHA functional class, who have an indication for ventricular pacing and } \\
\text { high-degree AV block, in order to reduce morbidity. }\end{array}$ & I & A \\
CRT is recommended over RV pacing in patients with HFrEF who require pacing & I & A \\
$\begin{array}{l}\text { with a high-degree of AV block. } \\
\text { Pacing modes that avoid inducing or worsening ventricular dyssynchrony should } \\
\text { be considered for patients with HFrEF who require ventricular pacing without } \\
\text { high-degree AV block. }\end{array}$ & IIa & C \\
\hline
\end{tabular}

ESC European Society of Cardiology, $C R T$ cardiac resynchronization therapy, $H F r E F$ heart failure with reduced ejection fraction, NYHA New York Heart Association, $A V$ atrioventricular, $R V$ right ventricular significant trend in favor of CRT pacing vs. RV pacing. Additional analyses might identify subgroups of patients where CRT pacing shows a clear and statistically significant benefit. Interestingly, LVEF did not seem to have any influence on the combined primary outcome as the results were similar for LVEF $\leq 50$ vs. $>50 \%$. It is not immediately obvious why the BioPace study results differed to BLOCK HF; however, different patient demographics are likely to have played a role. Furthermore, patients in the BLOCK HF trial had a greater number of patients with LBBB (total $32.6 \%$, CRT pacing group $35.2 \%$, RV pacing group 29.8\%) compared to BioPace (total $17.2 \%$, CRT group $16.6 \%$, RV group $18.3 \%$ ) and lower LVEF, possibly indicating a cohort with more severe heart failure. Furthermore, AF is a recognized marker for underlying morbidity, and again more patients in the BLOCK HF trial had AF (total 52.8\%, CRT group 51.6\%, RV group $54.1 \%$ ) vs. BioPace (total $24.9 \%$, CRT group $24.9 \%$, RV group $24.8 \%$ ) indicating the higher morbidity in the BLOCK HF cohort. The long-awaited final published results from the BioPace investigators may help to better understand the results and differences to the BLOCK HF trial.

\section{The Role of CRT in Patients With Atrial Fibrillation Undergoing AV Node Ablation}

There have been several studies that have demonstrated better outcomes with CRT followed by AV node ablation than RV pacing in patients with symptomatic atrial fibrillation with rapid ventricular response [46, 47, 57-59]. In 2012, a metaanalysis of the aforementioned studies as well as two other similar studies found CRT pacing was associated with a significant reduction in hospitalizations for heart failure $(\mathrm{RR}=$ $0.38,95 \% \mathrm{CI}=0.17-0.85 ; P=0.02)$. Moreover, they established a non-significant reduction in mortality compared to $\mathrm{RV}$ pacing $(\mathrm{RR}=0.75,95 \% \mathrm{CI}=0.43-1.30 ; P=0.30)$ [59]. Conversely, there was no significant difference in Minnesota Living With Heart Failure Questionnaire Score or 6MWT distance between CRT and RV pacing groups. In 2010, Orlov et al. randomized 153 patients in a single-blinded trial and revealed a significant increase improvement in LVEF in the CRT pacing group; however, in the RV pacing group, there was a non-significant reduction in LVEF [58]. Similarly, Brignole et al. conducted a prospective, multicenter study (The Ablate and Pace in AF Trial) and randomized 186 patients who had undergone CRT device implantation and AV node ablation to receive either CRT $(n=97)$ with V-V interval optimization or RV apical pacing. Baseline demographics were similar to the PAVE study, and follow-up was a median of 20 months (interquartile range 11-24). The primary composite endpoint of death from heart failure, hospitalization due to heart failure, or worsening heart failure occurred in $11 \%$ patients in the CRT group and $26 \%$ patients in the RV group [CRT vs. RV group: subhazard ratio (SHR) 0.37 (95\% CI 0.18-0.73), $P=0.005$ ] [47]. Fewer patients had worsening heart failure in the CRT group compared to the RV group [SHR 0.27 (95\% CI 0.12-0.58), $P=0.001$ ] and fewer hospitalizations for heart failure [SHR 0.20 (95\% CI 0.06-0.72), $P=0.013$ ] [47]. There was, however, no significant difference in total mortality, although the authors concluded that CRT was superior to RV apical pacing in reducing the clinical manifestations of heart failure in patients requiring an AV node ablation for symptomatic AF [47]. The Left Ventricular-Based Cardiac Stimulation Post AV Nodal Ablation Evaluation (The PAVE study) was a prospective randomized controlled study that compared CRT pacing with RV pacing in 184 patients with NYHA functional class I to III heart failure (baseline LVEF $45 \% \pm 15 \%$ in the CRT group vs. $47 \% \pm 16 \%$ in the RV group) undergoing an AV node ablation for atrial fibrillation (AF) refractory to pharmacotherapy [46]. Patients undergoing ICD implantation were excluded. The PAVE study showed that patients randomized to CRT ( $n=103)$ had significant improvements in LVEF and 6MWT but not in quality of life parameters compared to the RV paced group. At 6 months post ablation, patients treated with CRT had a significant degree of improvement in 6MWT, 31\% above baseline $(82.9 \pm$ $94.7 \mathrm{~m}$ ), compared to patients receiving RV pacing, $24 \%$ above baseline $(61.2 \pm 90.0 \mathrm{~m})(P=0.04)$ [46]. At 6 months post ablation, the LVEF in the CRT group $(46 \pm 13 \%)$ was significantly greater in comparison to the RV pacing group 
$(41 \pm 13 \%, p=0.03)$ [46]. The LVEF remained stable for patients in the CRT group whereas in the RV pacing group, the LVEF deteriorated by $3.1 \%$ at 6 weeks $(P=0.04)$ and $3.7 \%$ at 6 months $(P=0.03)$ [46]. The authors concluded that CRT provided a significant improvement in 6MWT distance and LVEF compared to RV pacing in patients undergoing $\mathrm{AV}$ node ablation for AF. Furthermore, patients with LV systolic impairment or symptomatic heart failure derived the greatest benefit from CRT pacing [46].

BLOCK HF was a landmark US-based trial that revealed encouraging evidence that improved outcomes may be achieved with CRT pacing compared to RV apical pacing in patients with LVSD and AV block when a high percentage of RV pacing is anticipated $[9,15]$. As a result, in 2014, the United States Food and Drug Administration approved the use of CRT in patients with AV block associated with a high percentage of ventricular pacing, mild to moderate heart failure, and LVEF $\leq 50 \%$ [60]. In 2016, the ESC guidelines for the diagnosis and treatment of acute and chronic heart failure were updated recommending CRT over RV pacing for patients with high-degree AV block, heart failure with reduced ejection fraction (HFrEF), and NYHA I-IV functional class in order to reduce morbidity (1A evidence, Table 2$)[61 \bullet \bullet]$. Patients with $\mathrm{AF}$ were included in this guidance.

\section{Conclusions}

The role of CRT pacing in patients with AV block and impaired LV systolic function remains an important consideration. The BLOCK HF trial demonstrated better outcomes with CRT pacing over RV pacing in patients with LVSD and AV block in patients expected to have a high RV pacing burden. However, BLOCK HF failed to demonstrate any mortality benefit. The preliminary results of the European-based BioPace trial have not confirmed the same statistically significant benefit, although we are still awaiting the full results to be published. In the interim, CRT pacing seems to have a beneficial effect on LV reverse remodeling, systolic function, and clinical outcomes in patients with NYHA functional class I-III heart failure, moderate to severe LVSD, and AV block compared to RV pacing. However, it is less clear whether there is a similar benefit from CRT in patients with a high percentage of RV pacing who have normal or mild LVSD in the treatment of AV block.

\section{Compliance with Ethical Standards}

Conflict of Interest Justin Gould and Bradley Porter are on clinical research fellowship programs funded by Abbott.

Baldeep Sidhu is on a clinical research fellowship program funded by Medtronic Inc.

Christopher A. Rinaldi receives research funding and/or consultancy fees from Abbott, Medtronic Inc., Boston, and LivaNova outside of the submitted work.
Human and Animal Rights and Informed Consent This article does not contain any studies with human or animal subjects performed by any of the authors.

Open Access This article is distributed under the terms of the Creative Commons Attribution 4.0 International License (http:// creativecommons.org/licenses/by/4.0/), which permits unrestricted use, distribution, and reproduction in any medium, provided you give appropriate credit to the original author(s) and the source, provide a link to the Creative Commons license, and indicate if changes were made.

\section{References}

Papers of particular interest, published recently, have been highlighted as:

- Of importance

•• Of high importance

1. Connolly SJ, Kerr C, Gent M, Yusuf S. Dual-chamber versus ventricular pacing. Critical appraisal of current data. Circulation. 1996;94(3):578-83. https://doi.org/10.1161/01.CIR.94.3.578.

2. Nielsen JC, Andersen HR, Thomsen PE, Thuesen L, Mortensen PT, Vesterlund $\mathrm{T}$, et al. Heart failure and echocardiographic changes during long-term follow-up of patients with sick sinus syndrome randomized to single-chamber atrial or ventricular pacing. Circulation. 1998;97(10):987-95. https://doi.org/10.1161/01.CIR. 97.10.987.

3. Tantengco MVT, Thomas RL, Karpawich PP. Left ventricular dysfunction after long-term right ventricular apical pacing in the young. J Am Coll Cardiol. 2001;37(8):2093-100. https://doi.org/ 10.1016/S0735-1097(01)01302-X.

4. Tse HF, Yu C, Wong KK, Tsang V, Leung YL, Ho WY, Lau CP (2002) Functional abnormalities in patients with permanent right ventricular pacing: the effect of sites of electrical stimulation. J Am Coll Cardiol 40:1451-1458, 8, DOI: https://doi.org/10.1016/ S0735-1097(02)02169-1.

5. Wilkoff BL, Cook JR, Epstein AE, Greene HL, Hallstrom AP, Hsia $\mathrm{H}$, et al. Dual-chamber pacing or ventricular backup pacing in patients with an implantable defibrillator: the Dual Chamber and VVI Implantable Defibrillator (DAVID) Trial. JAMA. 2002;288(24): 3115-23.

6. Lamas GA, Lee KL, Sweeney MO, Silverman R, Leon A, Yee R, et al. Ventricular pacing or dual-chamber pacing for sinus-node dysfunction. N Engl J Med. 2002;346(24):1854-62. https://doi. org/10.1056/NEJMoa013040.

7. Nielsen JC, Kristensen L, Andersen HR, Mortensen PT, Pedersen OL, Pedersen AK (2003) A randomized comparison of atrial and dual-chamber pacing in 177 consecutive patients with sick sinus syndrome: echocardiographic and clinical outcome. J Am Coll Cardiol 42:614-623, 4, DOI: https://doi.org/10.1016/S07351097(03)00757-5.

8. Thambo J-B, Bordachar P, Garrigue S, et al. Detrimental ventricular remodeling in patients with congenital complete heart block and chronic right ventricular apical pacing. Circulation. 2004;110: 3766-72.

9. Fang F, Sanderson JE, Yu C-M. Should all patients with heart block receive biventricular pacing? All heart block patients with a pacemaker indication should receive biventricular pacing: one move, double the gains? Circ Arrhythm Electrophysiol. 2015;8(3):7229. https://doi.org/10.1161/CIRCEP.114.000626. 
10. Abraham WT, Hayes DL. Cardiac resynchronization therapy for heart failure. Circulation. 2003;108(21):2596-603. https://doi.org/ 10.1161/01.CIR.0000096580.26969.9A.

11. Tracy CM, Epstein AE, Darbar D, DiMarco JP, Dunbar SB, Estes NAM III, et al. 2012 ACCF/AHA/HRS focused update of the 2008 guidelines for device-based therapy of cardiac rhythm abnormalities. J Am Coll Cardiol. 2012;60(14):1297-313. https://doi.org/10. 1016/j.jacc.2012.07.009.

12. Bristow MR, Saxon LA, Boehmer J, Krueger S, Kass d, de Marco $\mathrm{T}$, et al. Cardiac-resynchronization therapy with or without an implantable defibrillator in advanced chronic heart failure. N Engl $\mathrm{J}$ Med. 2004;350(21):2140-50. https://doi.org/10.1056/ NEJMoa032423.

13. Cleland JGF, Daubert J-C, Erdmann E, Freemantle N, Gras D, Kappenberger L, et al. The effect of cardiac resynchronization on morbidity and mortality in heart failure. N Engl J Med. 2005;352(15):1539-49. https://doi.org/10.1056/NEJMoa050496.

14.• Curtis AB, Worley SJ, Adamson PB, Chung ES, Niazi I, Sherfesee $\mathrm{L}$, et al. Biventricular pacing for atrioventricular block and systolic dysfunction for the Biventricular versus Right Ventricular Pacing in Heart Failure Patients with Atrioventricular Block (BLOCK HF) trial investigators. N Engl J Med. 2013;17368:1585-93. Landmark trial that demonstrated better outcomes with CRT pacing over RV pacing in patients with LVSD and AV block who were expected to have a high RV pacing burden, but failed to demonstrate a mortality benefit.

15. Beck $H$, Curtis $A B$. Right ventricular versus biventricular pacing for heart failure and atrioventricular block. Curr Heart Fail Rep. 2016;13(5):230-6. https://doi.org/10.1007/s11897-016-0299-3.

16. Fang F, Chan JY-S, Yip GW-K, Xie J-M, Zhang Q, Fung JW-H, et al. Prevalence and determinants of left ventricular systolic dyssynchrony in patients with normal ejection fraction received right ventricular apical pacing: a real-time three-dimensional echocardiographic study. Eur J Echocardiogr. 2010;11(2):109-18. https://doi.org/10.1093/ejechocard/jep171.

17. Fang F, Zhang Q, Chan JY-S, Razali O, Azlan H, Chan HC-K, et al. Early pacing-induced systolic dyssynchrony is a strong predictor of left ventricular adverse remodeling: analysis from the Pacing to Avoid Cardiac Enlargement (PACE) trial. Int J Cardiol. 2013;168(2):723-8. https://doi.org/10.1016/j.ijcard.2012.08.005.

18. Maurer G, Torres MAR, Corday E, Haendchen RV, Meerbaum S. Two-dimensional echocardiographic contrast assessment of pacinginduced mitral regurgitation: relation to altered regional left ventricular function. J Am Coll Cardiol. 1984;3(4):986-91. https://doi.org/ 10.1016/S0735-1097(84)80357-5.

19. van Oosterhout MF, Prinzen FW, Arts T, Schreuder JJ, Vanagt WY, Cleutjens JP, et al. Asynchronous electrical activation induces asymmetrical hypertrophy of the left ventricular wall. Circulation. 1998;98(6):588-95. https://doi.org/10.1161/01.CIR.98.6.588.

20. Barold SS, Ovsyshcher IE. Pacemaker-induced mitral regurgitation. Pacing Clin Electrophysiol. 2005;28:357-60.

21. Vernooy K, Dijkman B, Cheriex EC, Prinzen FW, Crijns HJGM. Ventricular remodeling during long-term right ventricular pacing following his bundle ablation. Am J Cardiol. 2006;97(8):1223-7. https://doi.org/10.1016/j.amjcard.2005.11.044.

22. PP KARPAWICH, RABAH R, JE HAAS. Altered cardiac histology following apical right ventricular pacing in patients with congenital atrioventricular block. Pacing Clin Electrophysiol. 1999;22: 1372-7.

23. Sweeney MO, Hellkamp AS, Ellenbogen KA, Greenspon AJ, Freedman RA, Lee KL, et al. Adverse effect of ventricular pacing on heart failure and atrial fibrillation among patients with normal baseline QRS duration in a clinical trial of pacemaker therapy for sinus node dysfunction. Circulation. 2003;107(23):2932-7. https:// doi.org/10.1161/01.CIR.0000072769.17295.B1.
24. Moss AJ, Zareba W, Hall WJ, Klein H, Wilber DJ, Cannom DS, et al. Prophylactic implantation of a defibrillator in patients with myocardial infarction and reduced ejection fraction. N Engl J Med. 2002;346(12):877-83. https://doi.org/10.1056/NEJMoa013474.

25. Barsheshet A, Moss AJ, McNitt S, Jons C, Glikson M, Klein HU, et al. Long-term implications of cumulative right ventricular pacing among patients with an implantable cardioverter-defibrillator. Heart Rhythm. 2011;8(2):212-8 A important subsequent subanalysis of MADIT II which found that patients with a high RV pacing percentage had a significantly increased risk of new or worsening heart failure. https://doi.org/10.1016/j.hrthm.2010.10.035.

26. Barold SS, Israel CW. The changing landscape of cardiac pacing. Herzschrittmachertherapie + Elektrophysiologie. 2015;26(1):32-8. https://doi.org/10.1007/s00399-014-0346-2.

27. Tops LF, Schalij MJ, Bax JJ. The effects of right ventricular apical pacing on ventricular function and Dyssynchrony. J Am Coll Cardiol. 2009;54(9):764-76. https://doi.org/10.1016/j.jacc.2009. 06.006.

28. Akerström F, Pachón M, Puchol A, Jiménez-López J, Segovia D, Rodríguez-Padial L, et al. Chronic right ventricular apical pacing: adverse effects and current therapeutic strategies to minimize them. Int J Cardiol. 2014;173:351-60.

29. Prinzen FW, Hunter WC, Wyman BT, McVeigh ER. Mapping of regional myocardial strain and work during ventricular pacing: experimental study using magnetic resonance imaging tagging. J Am Coll Cardiol. 1999;33(6):1735-42. https://doi.org/10.1016/S07351097(99)00068-6.

30. Prinzen FW, Peschar M. Relation between the pacing induced sequence of activation and left ventricular pump function in animals. Pacing Clin Electrophysiol. 2002;25(4):484-98. https://doi.org/10. 1046/j.1460-9592.2002.00484.x.

31. Lupi G, Sassone B, Badano L, et al. Effects of right ventricular pacing on intra-left ventricular electromechanical activation in patients with native narrow QRS. Am J Cardiol. 2006;98:219-22.

32. Lieberman R, Padeletti L, Schreuder J, Jackson K, Michelucci A, Colella A, et al. Ventricular pacing lead location alters systemic hemodynamics and left ventricular function in patients with and without reduced ejection fraction. J Am Coll Cardiol. 2006;48: $1634-41$.

33. Albertsen AE, Nielsen JC, Poulsen SH, Mortensen PT, Pedersen AK, Hansen PS, et al. Biventricular pacing preserves left ventricular performance in patients with high-grade atrio-ventricular block: a randomized comparison with $\mathrm{DDD}(\mathrm{R})$ pacing in 50 consecutive patients. Europace. 2008;10(3):314-20. https://doi.org/10.1093/ europace/eun023.

34. Liu W-H, Chen M-C, Chen Y-L, Guo B-F, Pan K-L, Yang C-H, et al. Right ventricular apical pacing acutely impairs left ventricular function and induces mechanical dyssynchrony in patients with sick sinus syndrome: a real-time three-dimensional echocardiographic study. J Am Soc Echocardiogr. 2008;21(3):224-9. https://doi.org/ 10.1016/j.echo.2007.08.045.

35. Badke FR, Boinay P, Covell JW. Effects of ventricular pacing on regional left ventricular performance in the dog. Am J Phys. 1980;238:H858-67.

36. Tse HF, Lau CP. Long-term effect of right ventricular pacing on myocardial perfusion and function. J Am Coll Cardiol. 1997;29(4):744-9. https://doi.org/10.1016/S0735-1097(96)005864.

37. Skalidis EI, Kochiadakis GE, Koukouraki SI, Chrysostomakis SI, Igoumenidis NE, Karkavitsas NS, et al. Myocardial perfusion in patients with permanent ventricular pacing and normal coronary arteries. J Am Coll Cardiol. 2001;37(1):124-9. https://doi.org/10. 1016/S0735-1097(00)01096-2.

38. Kaye GC, Linker NJ, Marwick TH, Pollock L, Graham L, Pouliot E, et al. Effect of right ventricular pacing lead site on left ventricular function in patients with high-grade atrioventricular block: results 
of the Protect-Pace study. Eur Heart J. 2015;36(14):856-62. Important trial comparing RV apical versus RV high septal pacing. https://doi.org/10.1093/eurheartj/ehu304.

39. El-Sherif N, Amay-Y-Leon F, Schonfield C, Scherlag BJ, Rosen K, Lazzara R, et al. Normalization of bundle branch block patterns by distal His bundle pacing. Clinical and experimental evidence of longitudinal dissociation in the pathologic his bundle. Circulation. 1978;57(3):473-83. https://doi.org/10.1161/01.CIR.57.3.473.

40. Deshmukh P, Casavant DA, Romanyshyn M, Anderson K. Permanent, direct His-bundle pacing: a novel approach to cardiac pacing in patients with normal His-Purkinje activation. Circulation. 2000;101(8):869-77. https://doi.org/10.1161/01.CIR.101.8.869.

41. Deshmukh PM, Romanyshyn M. Direct His-bundle pacing: present and future. Pacing Clin Electrophysiol. 2004;27(6p2):862-70. https://doi.org/10.1111/j.1540-8159.2004.00548.x.

42. Barba-Pichardo R, Morina-Vazquez P, Fernandez-Gomez JM, Venegas-Gamero J, Herrera-Carranza M. Permanent His-bundle pacing: seeking physiological ventricular pacing. Europace. 2010;12:527-33.

43. Kronborg MB, Mortensen PT, Gerdes JC, Jensen HK, Nielsen JC. His and para-His pacing in AV block: feasibility and electrocardiographic findings. J Interv Card Electrophysiol. 2011;31(3):255-62. https://doi.org/10.1007/s10840-011-9565-1.

44. Barba-Pichardo R, Manovel Sánchez A, Fernández-Gómez JM, Moriña-Vázquez P, Venegas-Gamero J, Herrera-Carranza M. Ventricular resynchronization therapy by direct His-bundle pacing using an internal cardioverter defibrillator. EP Eur. 2013;15(1):838. https://doi.org/10.1093/europace/eus228.

45. Sharma PS, Dandamudi G, Naperkowski A, Oren JW, Storm RH, Ellenbogen KA, et al. Permanent His-bundle pacing is feasible, safe, and superior to right ventricular pacing in routine clinical practice. Hear Rhythm. 2015;12(2):305-12. https://doi.org/10. 1016/j.hrthm.2014.10.021.

46. Doshi RN, Daoud EG, Fellows C, Turk K, Duran A, Hamdan MH, et al. Left ventricular-based cardiac stimulation post AV nodal ablation evaluation (the PAVE study). J Cardiovasc Electrophysiol. 2005;16(11):1160-5. https://doi.org/10.1111/j.1540-8167.2005. 50062.x.

47. Brignole M, Botto G, Mont L, Iacopino S, De Marchi G, Oddone D, et al. Cardiac resynchronization therapy in patients undergoing atrioventricular junction ablation for permanent atrial fibrillation: a randomized trial. Eur Heart J. 2011;32(19):2420-9. https://doi. org/10.1093/eurheartj/ehr162.

48. Stockburger M, Gómez-Doblas JJ, Lamas G, Alzueta J, FernándezLozano I, Cobo E, et al. Preventing ventricular dysfunction in pacemaker patients without advanced heart failure: results from a multicentre international randomized trial (PREVENT-HF). Eur J Heart Fail. 2011;13(6):633-41. https://doi.org/10.1093/eurjhf/ hfr041.

49. Yu C-M, Fang F, Luo X-X, Zhang Q, Azlan H, Razali O. Long-term follow-up results of the Pacing to Avoid Cardiac Enlargement (PACE) trial. Eur J Heart Fail. 2014;16(9):1016-25. https://doi. org/10.1002/ejhf.157.

50. Kindermann M, Hennen B, Jung J, Geisel J, Böhm M, Fröhlig G. Biventricular versus conventional right ventricular stimulation for patients with standard pacing indication and left ventricular dysfunction. J Am Coll Cardiol. 2006;47(10):1927-37. https://doi. org/10.1016/j.jacc.2005.12.056.
51. Filho MM, de Siqueira SF, Costa R, Greco OT, Moreira LF, D'avila A, et al. Conventional versus biventricular pacing in heart failure and Bradyarrhythmia: the COMBAT study. J Card Fail. 2010;16(4): 293-300. https://doi.org/10.1016/j.cardfail.2009.12.008.

52.•Blanc JJ, Funck RC, Lunati M et al. (2014). http:// clinicaltrialresults.org/Slides/TCT\%202014/Blanc_Biopace.pdf BioPace Trial Investigators and Coordinators Biventricular Pacing for Atrio-ventricular Block to Prevent Cardiac Desynchronization. Important European trial comparing RV pacing to CRT pacing with a similar cohort of patients as BLOCK HF. The website summarizes the preliminary results of the BioPace trial. No statistically significant difference was found between CRT pacing and RV pacing for first hospitalization due to heart failure or time to death.

53. Yu C-M, Chan JY-S, Zhang Q, Omar R, Yip GW-K, Hussin A, et al. Biventricular pacing in patients with bradycardia and normal ejection fraction. N Engl J Med. 2009;361(22):2123-34. https://doi.org/ 10.1056/NEJMoa0907555.

54. Chan JY-S, Fang F, Zhang Q, Fung JW-H, Razali O, Azlan H, et al. Biventricular pacing is superior to right ventricular pacing in bradycardia patients with preserved systolic function: 2-year results of the PACE trial. Eur Heart J. 2011;32(20):2533-40. https://doi.org/ 10.1093/eurheartj/ehr336.

55. Funck RC, Mueller H-H, Lunati M, Piorkowski C, De Roy L, Paul $\mathrm{V}$, et al. Characteristics of a large sample of candidates for permanent ventricular pacing included in the Biventricular Pacing for Atrio-ventricular Block to Prevent Cardiac Desynchronization Study (BioPace). EP Eur. 2014;16(3):354-62. https://doi.org/10. 1093/europace/eut343.

56. St. John Sutton M, Plappert T, Adamson PB, Li P, Christman SA, Chung ES, et al. Left ventricular reverse remodeling with biventricular versus right ventricular pacing in patients with atrioventricular block and heart failure in the BLOCK HF trial. Circ Hear Fail. 2015;8(3):510-8. https://doi.org/10.1161/ CIRCHEARTFAILURE.114.001626.

57. Brignole M, Gammage M, Puggioni E, et al. Comparative assessment of right, left, and biventricular pacing in patients with permanent atrial fibrillation. Eur Heart J. 2005;26:712-22.

58. Orlov MV, Gardin JM, Slawsky M, Bess RL, Cohen G, Bailey W, et al. Biventricular pacing improves cardiac function and prevents further left atrial remodeling in patients with symptomatic atrial fibrillation after atrioventricular node ablation. Am Heart J. 2010;159(2):264-70. https://doi.org/10.1016/j.ahj.2009.11.012.

59. Stavrakis S, Garabelli P, Reynolds DW. Cardiac resynchronization therapy after atrioventricular junction ablation for symptomatic atrial fibrillation: a meta-analysis. Europace. 2012;14:1490-7.

60. Summary of Safety and Effectiveness Data (SSED) (2014). http:// www.accessdata.fda.gov/cdrh docs/pdf/p010031s381b.pdf

61.• Ponikowski P, Voors AA, Anker SD, et al. 2016 ESC Guidelines for the diagnosis and treatment of acute and chronic heart failure. Eur J Heart Fail. 2016;18:891-975. European Society of Cardiology Guidelines for the diagnosis and treatment of acute and chronic heart failure were updated in $\mathbf{2 0 1 6}$ and recommend CRT over RV pacing for patients with high-degree AV block, HFrEF, and NYHA I-IV functional class in order to reduce morbidity $(1 \mathrm{~A}$ evidence). 